\section{Examining Summer Laboratory Research Apprenticeships for High School Students as a Factor in Entry to MD/PhD Programs at Matriculation}

\author{
Robert H. Tai, ${ }^{\dagger *}$ Xiaoqing Kong, $^{\dagger}$ Claire E. Mitchell, ${ }^{\dagger}$ Katherine P. Dabney, ${ }^{\star}$ \\ Daniel M. Read, ${ }^{\dagger}$ Donna B. Jeffe, $\$$ Dorothy A. Andriole, $\$$ and Heather D. Wathington ${ }^{\dagger}$ \\ ${ }^{\dagger}$ Curry School of Education, University of Virginia, Charlottesville, VA 22904; ‘School of Education, \\ Virginia Commonwealth University, Richmond, VA 23284; "School of Medicine, Washington \\ University, St. Louis, MO 63110
}

\begin{abstract}
Do summer laboratory research apprenticeships during high school have an impact on entry into MD/PhD programs? Apart from the nearly decade-long span of time between high school and matriculation into an MD/PhD program, young people have many life-shaping experiences that presumably impact their education and career trajectories. This quantitative study ( $n=236,432$ ) examines the connection between early laboratory research apprenticeship experiences at the high school level and matriculation into one of the more rigorous educational programs for scientific research training. The span of time covered by this analysis reaches across more than a decade, examining the potential importance of research experiences during the precollege years in the educational trajectory of young people. Intertwined with this question on research experiences is a second major concern regarding diversity in the life sciences research corps. Diversity in this wide-ranging discipline refers specifically to the underrepresentation of Blacks/African Americans, Hispanics/Latino/as, and American Indians/Alaska Natives among the ranks of research scientists. Thus, this study includes analyses that specifically focus on research apprenticeships of Blacks/African Americans and Hispanics/Latino/as and their entrance into MD/ PhD programs.
\end{abstract}

\section{INTRODUCTION}

The lack of diversity within the scientific research workforce is a pervasive concern (Tabak and Collins, 2011). Within the corps of physician-scientists in the United States, only $7 \%$ of $\mathrm{MD} / \mathrm{PhD}$ program graduates identified as either Black/African American or Hispanic/Latino/a, or American Indian/Alaska Native (Andriole et al., 2008); by contrast, most recent census data indicate that $28.9 \%$ of the U.S. population identifies as members of these racial/ethnic groups (Humes et al., 2011). A major reason for this disparity is the failure of minority science, technology, engineering, and mathematics (STEM) majors to persist to degree completion and/or continue on to graduate study. This attrition is particularly problematic given that minority students entering college are as likely as white students to report intentions to pursue a science-related degree but are less likely to graduate in their intended majors and less likely to pursue advanced degrees in one of the science and engineering-related fields (National Science Board, 2007; National Science Foundation, 2013). Recent studies have reported that underrepresented minority students earned $17.8 \%$ of the baccalaureate degrees, $13.1 \%$ of the master's degrees, and $6.9 \%$ of the doctoral degrees conferred in science and engineering-related fields (National Science Foundation, 2013). A better understanding the factors that contribute to the persistence of minorities underrepresented in STEM is critical for the United States to maintain its global competitiveness in science and technology and to attain a diverse biomedical workforce
Graham F. Hatfull, Monitoring Editor Submitted July 31, 2015; Revised December 19, 2016; Accepted January 5, 2017

CBE Life Sci Educ June 1, 2017 16:ar37

DOI:10.1187/cbe.15-07-0161

*Address correspondence to: Robert H. Tai (rht6h@virginia.edu).

(c) 2017 R. H. Tai et al. CBE-Life Sciences Education () 2017 The American Society for Cell Biology. This article is distributed by The American Society for Cell Biology under license from the author(s). It is available to the public under an Attribution-Noncommercial-Share Alike 3.0 Unported Creative Commons License (http:// creativecommons.org/licenses/by-nc-sa/3.0). "ASCB®" and "The American Society for Cell Biology ${ }^{\circledR}$ are registered trademarks of The American Society for Cell Biology. 
that can support the national development of culturally inclusive research agendas (Duffus et al., 2014).

One important means of supporting minority pursuit of and persistence in STEM-related academic programs of study is the high school summer laboratory research apprenticeship (HSSLRA) experience. Research has found that such programs can bolster student science self-identity and self-efficacy (Hunter et al., 2006; Bakken et al., 2010; Herrera and Hurtado, 2011) and provide much-needed mentorship, support, and motivation (Chubin et al., 2009; Rohrbaugh and Corces, 2011). In light of the federal investment in these activities through the National Institutes of Health (NIH) Science Education Partnership Awards, several policy-relevant questions remain to be addressed. Do these precollege experiences work? Could these experiences be an effective tool for increasing diversity in the scientific research workforce?

For the purposes of this study, we concentrated on a particular subset of the emerging biomedical research workforce: medical school students enrolled in $\mathrm{MD} / \mathrm{PhD}$ programs (i.e., $\mathrm{MD} / \mathrm{PhD}$ program enrollees). In this analysis, we examined data collected from and about a national cohort of students who had considered careers in medicine to address the following two questions:

1. Do individuals who report engaging in a HSSLRA and matriculate into $\mathrm{MD} / \mathrm{PhD}$ programs have a greater likelihood of graduating than individuals who do not?

2. Is participation in a HSSLRA associated with a greater likelihood of matriculation into $\mathrm{MD} / \mathrm{PhD}$ programs among underrepresented minorities?

We compared $\mathrm{MD} / \mathrm{PhD}$ program enrollee rates among individuals who reported participation in HSSLRA experiences with those for individuals who did not across four racial/ethnic demographic groups. We also included college laboratory research apprenticeship (CLRA) experiences in this analysis. We controlled for differences related to sex, parental occupation as a physician, and first-attempt Medical College Admission Test (MCAT) composite score as a measure of academic performance.

\section{LITERATURE REVIEW}

One approach to addressing the lack of diversity in the scientific workforce is to intervene by attracting individuals from underrepresented groups earlier in their academic trajectories. This approach is supported by existing research that suggests early interest in science is associated with greater likelihood of earning baccalaureate degrees in the life sciences, physical sciences, and engineering (Tai et al., 2006). In their logistic regression analysis of data from the National Education Longitudinal Study of 1988, which included 1988 survey data from students in eighth grade who indicated their future career preferences at age 30 and data for those who obtained baccalaureate degrees from 4-year institutions by the year 2000, Tai et al. (2006) found that students reporting an interest in science careers in eighth grade were three times more likely to obtain a college degree in science compared with those who did not show an initial interest. Additional research has corroborated these findings, particularly as they relate to the importance of the middle and high school years for STEM interest development. In their case study of 33 high school students, Aschbacher et al. (2010) concluded that students who were interested in science, engineering, or medicine majors or careers most often attributed this to science teachers and experiences that stimulated and inspired their interest in science. More recent quasi-experimental research by Knezek et al. (2013) on the impact of hands-on STEM projects on students' content knowledge and perceptions found that such activities not only bolster students' content knowledge but also influence their perceptions about STEM subjects and careers.

Further studies examining science interest have provided evidence for the effectiveness of out-of-school time (OST) activities (Bauer and Bennett, 2003; Sackes et al., 2009) and the influence of teachers, parents, and peers on students' science attitudes (Rodrigues et al., 2009; Sevinc et al., 2011). For example, one study (Dabney et al., 2012) found that participation in OST science clubs and competitions had a strong positive association with college STEM career interest. And research by Dabney et al. (2016) further indicated that families with higher parental education have a greater likelihood of participating in OST science, which then associated with an earlier initial interest in science. Longitudinal studies of OST science experiences have been examined as well, though far more infrequently. Kong et al. (2013) determined that middle school students who participated in a second year of science summer camps, having had a similar experience the year before, were much more likely to indicate science or engineering as a future career compared with students without prior experience. Regardless of these early OST science findings, the majority of research on the pursuit of STEM career fields and attainment of degrees still mainly points toward the importance of high school factors and experiences (Maltese and Tai, 2011).

One particular method of engaging minority youth with science is the HSSLRA experience. While more rigorous research has examined the impact of student participation in research at the postsecondary level (Lopatto, 2004; Russell et al., 2007; Hernandez et al., 2012), the body of literature examining outcomes pertaining to high school research participation remains somewhat limited. Student research apprenticeships in science at the secondary level are, by and large, consistent with two models: extracurricular, OST summer programs, which engage high school students with research experiences over a period of time, or classroom-based student-scientist partnerships, which provide opportunities for high school students to work on actual research projects of practicing scientists (Sadler et al., 2010). Despite their differences, both models afford students an opportunity to engage in an ongoing research project over an extended period of time. Some programs may also incorporate college knowledge instruction and test preparation so as to prepare students to navigate the postsecondary environment (Rohrbaugh and Corces, 2011). In her study of 54 minority high school students who participated in a health-related research apprenticeship at Ohio State University, Davis (1999) found that program participation positively impacted career decision making, as evidenced by a longitudinal follow-up of the sample, $68 \%$ of whom chose to pursue a health-related academic path following high school. Abraham's (2002) qualitative study of 75 high school students who participated in a research apprenticeship at a remote field station contextualized and corroborated these findings; participants reported developing more positive views of scientists and the scientific 
community and a subsequent increase in their interest in and involvement with the sciences.

Researchers have posited that these types of research apprenticeships are effective due to their immersive nature and their ability to offer high school students access to role models and experiences not typically found in a formal school classroom (Abraham, 2002; Winkleby, 2007). To be sure, most high school students, particularly minority students or those from low-income school districts, are not given opportunities to engage in authentic scientific endeavors in the formal classroom setting. High school research apprenticeship experiences thus hold promise in that they allow students to work directly with research scientists. Further study is needed, however, to examine the potential impact that high school experiences with research may have on students' subsequent entry into the biomedical research corps.

\section{METHODS}

The outcome variable is "enrollment in an $\mathrm{MD} / \mathrm{PhD}$ program" ( 1 = yes, 0 =no); enrollment in these types of physician-scientist programs is an important entry point into the ranks of the biomedical research corps in the life sciences. The predictor and control variables included in the analysis are listed in Table 1. The primary predictor variable is "participation in HSSLRA" ( 1 = yes; $0=$ no). The five control variables/control variable groups were included in the analysis. "Participation in CLRA" ( 1 = yes, $0=$ no) was included in the analysis, because college laboratory experience offers an additional point of comparison accounting for laboratory experiences apart from the high school level. Research laboratory experience is valued in MD/ $\mathrm{PhD}$ admissions. By including CLRA, the analysis controls for laboratory research experience, allowing for a direct comparison of individuals reporting backgrounds with respect to HSSLRA and CLRA experiences from the four categories shown in Table 2. "Female" ( 1 =yes, $0=$ male) was included to account for differences between males and females. "Race/ethnicitywhite" ( 1 =yes, $0=$ no), "race ethnicity-Black" ( 1 =yes, $0=$ no), "race ethnicity-Hispanic" ( 1 = yes, $0=$ no), and "race ethnicityAsian/Pacific Islander" ( $1=$ yes, $0=$ no) were included to account for potential differences across different gross race/ ethnicity groupings. "parental occupation as a physician"
TABLE 2. Cross-tabulation of HSSLRA experience and CLRA apprenticeship experience

\begin{tabular}{llccr}
\hline \multirow{2}{*}{$\begin{array}{l}\text { Cross- } \\
\text { tabulation }\end{array}$} & \multicolumn{2}{c}{ CLRA } & \\
\cline { 2 - 4 } HSSLRA & No & No & Yes & Total sample \\
\hline & Yes & $7,319(3.1 \%)$ & $13,412(5.7 \%)$ & \\
& & & & $236,432(100 \%)$
\end{tabular}

( 1 = yes, $0=$ no) was included to account for potential differences due to parental influences, "MCAT score" was included to account for differences in academic achievement level among participants, because entry into an $\mathrm{MD} / \mathrm{PhD}$ program is highly competitive and academic achievement is used as a criterion for admissions.

The data set used in this study was created by merging records of individualized data from the Association of American Medical Colleges (AAMC) Pre-Medical College Admission Test Questionnaire (PMQ) and the Student Record System (SRS). The PMQ is a self-report survey completed by individuals who have registered for the MCAT. We included PMQ responses about sex, race/ethnicity, parental occupation, and laboratory research apprenticeship participation in high school and college. The SRS houses medical college enrollment information and MCAT scores. These are collected through administrative means and are not self-reported by respondents. All data were linked for individual PMQ respondents, with duplications removed and deidentified for analysis. We used data from the PMQ for the years 2001-2006, which included respondent-reported participation in SLRA programs in high school and college. The SRS data were used to determine whether the respondent enrolled in an $\mathrm{MD} / \mathrm{PhD}$ program at the time of medical school matriculation, for the years 2001-2011, allowing a minimum of 5 years for the most recent PMQ respondents in 2006 to choose the $\mathrm{MD} / \mathrm{PhD}$ career path at matriculation, as MCAT examinees who ultimately matriculate in medical school may not do so for quite a few years after the initial MCAT attempt.

The overall sample size is 262,813 individuals. We chose to concentrate our analysis on the following four racial/ ethnic groups: white (non-Hispanic); Black/African American

TABLE 1. Comparison of MD/PhD and non-MD/PhD groups (total sample size of $n=236,432$ )

\begin{tabular}{|c|c|c|c|}
\hline Variables & Description & $\mathrm{MD} / \mathrm{PhD} n(\%)$ & Non-MD/PhD $n(\%)$ \\
\hline Subgroup total & Total sample sizes for each subgroup & $3056(100)$ & $233,376(100)$ \\
\hline HSSLRA experience & $\begin{array}{l}\text { Respondent participated in a laboratory research apprenticeship for high } \\
\text { school students }\end{array}$ & $580(19.0)$ & $20,151(8.6)$ \\
\hline CLRA experience & $\begin{array}{l}\text { Respondent participated in a laboratory research apprenticeship for } \\
\text { college students }\end{array}$ & $1894(62.0)$ & $68,189(29.2)$ \\
\hline Female & Respondent is female & $1223(40.0)$ & $124,475(53.3)$ \\
\hline White & Respondent self-identified as white (non-Hispanic) & $2007(65.7)$ & $142,799(61.2)$ \\
\hline Black & Respondent self-identified as Black/African American (non-Hispanic) & $174(5.7)$ & $19,239(8.2)$ \\
\hline Hispanic & Respondent self-identified as Hispanic/Latino/a & $173(5.7)$ & $18,598(8.0)$ \\
\hline Asian/Pacific Islander & Respondent self-identified as Asian/Pacific Islander (non-Hispanic)? & $702(23.0)$ & $52,740(22.6)$ \\
\hline \multirow{2}{*}{$\begin{array}{l}\text { Parental occupation } \\
\quad \text { as a physician }\end{array}$} & Respondent indicated that at least one parent was a medical doctor & 479 (15.7) & $31,573(13.5)$ \\
\hline & & Mean (SD) & Mean (SD) \\
\hline MCAT score & Mean (SD) of respondents' first composite MCAT score & $32.9(4.4)$ & $24.9(6.6)$ \\
\hline
\end{tabular}


(non-Hispanic); Hispanic/Latino/a; and Asian/Pacific Islander (non-Hispanic). Because only three individuals in the American Indian/Alaska Native (non-Hispanic) demographic group were found to have enrolled in $\mathrm{MD} / \mathrm{PhD}$ programs, we did not include this group in our analysis. Our final sample was $n=$ 236,432 . Individual surveys deleted from the sample fell into three categories: race/ethnicity, sex status, and MCAT scores. With respect to race/ethnicity, 13,333 respondents who reported race/ethnicity as "other or multiple," 170 respondents who reported as American Indian/Alaska Native (non-Hispanic), and an additional 1335 respondents who did not report race/ethnicity status were list-wise deleted from the analysis. There were 344 respondents with missing data for sex status; and 11,199 respondents who did not have a valid MCAT score were also excluded. Before the analysis proceeded, missing data were examined for their potential impact. Of primary concern were the outcomes for the 1335 individuals who did not report their race/ethnicity but who may be members of racial/ethnic groups retained in the analysis. Upon examination of the other variables not missing from these individuals' survey responses, we did not discover any clustering with respect to the other variables that might suggest biasing. These 1335 individuals constituted $0.5 \%$ of the overall sample. In light of these two conclusions, we felt that the impact of these individuals' survey responses to the findings would be negligible and list-wise deleted these surveys from our analysis.

To address the research questions, we performed a multivariate logistic regression analysis with STATA 11.0 statistical software package using the maximum-likelihood estimation approach to estimate the fitted probability of an individual to enroll in an $\mathrm{MD} / \mathrm{PhD}$ program $(1=$ yes, $0=$ no). Logistic regression analysis may be used to produce an odds ratio that provides a direct measure of the rate of $\mathrm{MD} / \mathrm{PhD}$ program matriculation while also accounting for the effect of covariates on the model fit. The LRA predictors were dummy coded as 1) respondents who reported both HSSLRA and CLRA experiences; 2) respondents who reported only CLRA experiences; and 3) respondents who reported only HSSLRA experiences. The respondents who reported no laboratory research apprenticeship experience in either high school or college were treated as the reference group (baseline for comparison). The covariates included sex (female vs. male), race/ethnicity (Black/African American, Hispanic/Latino/a, and Asian/Pacific Islander vs. white), and parental occupation (at least one parent a physician vs. neither parent a physician), with the MCAT score included as a continuous variable. We fitted a series of nested logistic regression models. The approach of using nested models allows for a more direct examination of the impact that each additional variable is having on the model fit as it is added to the analysis. This approach allows researchers to identify potential problems with the analysis and to clearly identify the apparent "impact" of each new variable as it is introduced into the analysis. Once the final model was developed, we tested its stability by comparing model fitted across six subsamples disaggregated year by year.

Finally, to address the second research question, we took the aggregated data set and split it into four subsamples based on the four race/ethnicity demographic groupings. Given the substantial size of each subsample, there were no concerns regarding statistical power. These results are summarized in Table 3. We fitted the final model on these four subsamples in order to examine the stability of the final model within racial/ethnic group.

\section{LIMITATIONS}

This study's findings, as with all quantitative research, should be considered with respect to limitations. The authors note that some control variables were not included in our data set. The first was factors measuring pre-existing motivation or career plans that could potentially influence initial LRA participation. The second was data regarding background information on high schools and colleges attended (i.e., wealth and size) by our participants. These control variables were beyond the scope and focus of this study.

Finally, there was a lack of information on the specific experiences the students engaged in during LRA. While the study collected surveys from more than 30,000 participants, data were not collected by the AAMC survey regarding the actual activities in which students engaged. As a result, we can only claim that our findings reflect generalized experiences of the 30,000 participants. Further information and research on specific LRA activities that students engage in is warranted. Such research would shed much needed light on the array of laboratory responsibilities and interactions high school students have access to and could potentially benefit from.

\section{FINDINGS}

Table 1 displays comparisons between respondents who entered $\mathrm{MD} / \mathrm{PhD}$ programs $(n=3056)$ and respondents who did not $(n=233,376)$ regarding HSSLRA and CLRA participation, sex, race/ethnicity, parental occupation, and MCAT score. Note that the relative percentage of $\mathrm{MD} / \mathrm{PhD}$ students reporting HSSLRA participation is roughly double the percentage of non- $\mathrm{MD} / \mathrm{PhD}$ respondents. A similar doubling appears for $\mathrm{MD} / \mathrm{PhD}$ respondents reporting CLRA experiences compared with non-MD/PhD respondents. Lower percentages of female, Black/AfricanAmerican (non-Hispanic), and Hispanic/Latino/a respondents

TABLE 3. Comparison across race/ethnicity groups of odds ratios of respondents matriculating in an MD/PhD program for three LRA experience groups for model 5

\begin{tabular}{lccccc}
\hline LRA & 2001-2006 Dataset & White & Black/African American & Hispanic/Latino/a & Asian and Pacific Islander \\
\hline Both HSSLRA and CLRA & $4.50^{* * *}$ & $5.55^{* * *}$ & $3.60^{* * *}$ & $5.37^{* * *}$ & $3.02^{* * * *}$ \\
Only CLRA & $2.76^{* * *}$ & $3.00^{* * *}$ & $2.82^{* * *}$ & $2.55^{* * *}$ & $2.14^{* * * *}$ \\
Only HSSLRA & $1.10^{\mathrm{ns}}$ & $0.98^{\mathrm{ns}}$ & $0.71^{\mathrm{ns}}$ & $0.86^{\mathrm{ns}}$ & $1.36^{\mathrm{ns}}$ \\
Sample size $(n)$ & 236,432 & 144,806 & 19,413 & 18,771 & 53,442 \\
\hline
\end{tabular}

$* * * p<0.001 ;$ ns, not significant. 
TABLE 4. Parameter estimates of nested multivariate logistic regression models displaying the fitted relationship on whether a PMQ respondent enrolled in an MD/PhD program (total sample size of $n=236,432)^{\text {a }}$

\begin{tabular}{|c|c|c|c|c|c|c|}
\hline & Null & Model 1 & Model 2 & Model 3 & Model 4 & Model 5 \\
\hline & $\begin{array}{c}\text { Coefficient } \\
\text { (SE) }\end{array}$ & $\begin{array}{l}\text { Coefficient } \\
\text { (SE) }\end{array}$ & $\begin{array}{l}\text { Coefficient } \\
\text { (SE) }\end{array}$ & $\begin{array}{l}\text { Coefficient } \\
\text { (SE) }\end{array}$ & $\begin{array}{l}\text { Coefficient } \\
\text { (SE) }\end{array}$ & $\begin{array}{l}\text { Coefficient } \\
\text { (SE) }\end{array}$ \\
\hline \multicolumn{7}{|l|}{ LRA } \\
\hline Both HSSLRA and CLRA & & $1.76 * * *(0.05)$ & $1.77 * * *(0.05)$ & $1.82 * * *(0.05)$ & $1.82 * * *(0.05)$ & $1.50 * * *(0.06)$ \\
\hline Only CLRA & & $1.26 * * *(0.04)$ & $1.27 * * *(0.04)$ & $1.28 * * *(0.04)$ & $1.28 * * *(0.04)$ & $1.01 * * *(0.04)$ \\
\hline Only HSSLRA & & $0.10^{\text {ns }}(0.14)$ & $0.12^{\text {ns }}(0.14)$ & $0.18^{\text {ns }}(0.14)$ & $0.17^{\mathrm{ns}}(0.14)$ & $0.10^{\text {ns }}(0.14)$ \\
\hline Female & & & + & + & + & + \\
\hline \multicolumn{7}{|l|}{ Race/ethnicity } \\
\hline Black/African American & & & & + & + & + \\
\hline Hispanic/Latino/a & & & & + & + & + \\
\hline Asian/Pacific Islander & & & & + & + & + \\
\hline Parental occupation & & & & & + & + \\
\hline MCAT score & & & & & & + \\
\hline Pseudo $R^{2}$ & 0.00 & 0.05 & 0.05 & 0.05 & 0.05 & 0.19 \\
\hline$-2 \mathrm{LL}$ & 32,651 & 31,183 & 30,948 & 30,882 & 30,882 & 26,489 \\
\hline
\end{tabular}

${ }^{\mathrm{a} A}$ plus sign (+) indicates variable included in model as a covariate.

$* * * p<0.001$; ns, not significant.

are in $\mathrm{MD} / \mathrm{PhD}$ programs than in the non-MD/PhD group. Also, as would be fully expected, the mean MCAT score among MD/ $\mathrm{PhD}$ respondents is significantly higher than among non-MD/ $\mathrm{PhD}$ respondents.

We continue with an examination of the cross-tabulation of HSSLRA and CLRA experiences (see Table 2). Here, we can see that about two-thirds of students who reported HSSLRA experiences also reported participating in CLRA experiences, while one-third of HSSLRA participants did not continue to pursue CLRA experiences. On the basis of Table 2, we computed a new four-category variable for analysis based on reported participation: "both HSSLRA and CLRA," "only CLRA," "only HSSLRA," and "neither HSSLRA nor CLRA (no LRA)."

Table 4 displays the results of the series of nested logistic regression models with each model including an additional covariate, allowing us to examine how the inclusion of each successive covariate influenced the overall model fit and other parameter estimates. This method of nesting models has two distinct advantages. First, this approach allowed for the testing of the model's goodness of fit with the negative two log-likelihood (-2LL) statistic. As the model better fits the data, the -2LL statistic decreases. Second, this approach allowed us to see how the inclusion of each successive covariate influenced the overall model and the other parameter estimates. Note that the results showed the three dummy-coded LRA variables (both HSSLRA and CLRA; only CLRA, and only HSSLRA) were stable throughout the process. While the LRA parameter estimates varied, the changes were limited.

To verify model fit, we evaluated each model's goodness of fit using the likelihood ratio test to determine whether an additional covariate (or set of covariates) improved the fit of the model from each successive nested model (Hosmer and Lemeshow, 1980; Menard, 2001). The difference in degrees of freedom using a $\chi_{(0.50)}^{2}$ distribution was used to determine whether the inclusion of a covariate resulted in a statistically significant improvement (Pedhazur, 1997). Individual parameter estimates were also evaluated by testing whether the individual $z$-statistics were statistically significant. On the basis of these results, we use model 5 from Table 4 as the final model going forward.

A characteristic of this data set is that it is an aggregation of a series of data sets collected over a span of 6 years from 20012006 for the PMQ, with follow-up data for MD/PhD program enrollment updated through 2012. Thus, we disaggregated the data and tested model 5 using each of the six data sets. This approach allows for a direct comparison of how model 5 performs with each independent subsample. Table 5 shows the odds ratios produced from model 5 of the aggregated data set (column 1) in comparison with the model 5 odds ratios for the six year-by-year disaggregated data sets (columns 2-7).

TABLE 5. Odds ratios of $P M Q$ respondents matriculating in an MD/PhD program for each of the three LRA participation groups compared with neither high school nor college LRA participation for the aggregated 2001-2006 data and for each of the six annual data sets ${ }^{a}$

\begin{tabular}{|c|c|c|c|c|c|c|c|}
\hline LRA & $\begin{array}{c}2001-2006 \\
\text { Data set }\end{array}$ & $\begin{array}{c}2001 \\
\text { Data set }\end{array}$ & $\begin{array}{c}2002 \\
\text { Data set }\end{array}$ & $\begin{array}{c}2003 \\
\text { Data set }\end{array}$ & $\begin{array}{c}2004 \\
\text { Data set }\end{array}$ & $\begin{array}{c}2005 \\
\text { Data set }\end{array}$ & $\begin{array}{c}2006 \\
\text { Data set }\end{array}$ \\
\hline Both HSSLRA and CLRA & $4.50 * * *$ & $3.91 * * *$ & $5.18 * * *$ & $4.32 * * *$ & $5.08 * * *$ & $4.14^{* * *}$ & $4.33 * * *$ \\
\hline Only CLRA & $2.76 * * *$ & $2.66 * * *$ & $3.49 * * *$ & $2.88 * * *$ & $3.03 * * *$ & $2.45 * * *$ & $2.21 * * *$ \\
\hline Only HSSLRA & $1.10^{\mathrm{ns}}$ & $1.59^{\mathrm{ns}}$ & $1.66^{\mathrm{ns}}$ & $0.65^{\mathrm{ns}}$ & $0.69^{\text {ns }}$ & $1.08^{\mathrm{ns}}$ & $1.15^{\mathrm{ns}}$ \\
\hline Sample size $(n)$ & 236,432 & 34,114 & 35,876 & 37,066 & 40,577 & 43,014 & 45,785 \\
\hline
\end{tabular}

aThe baseline comparison group is no LRA experience.

$* * * p<0.001$; ns, not significant. 


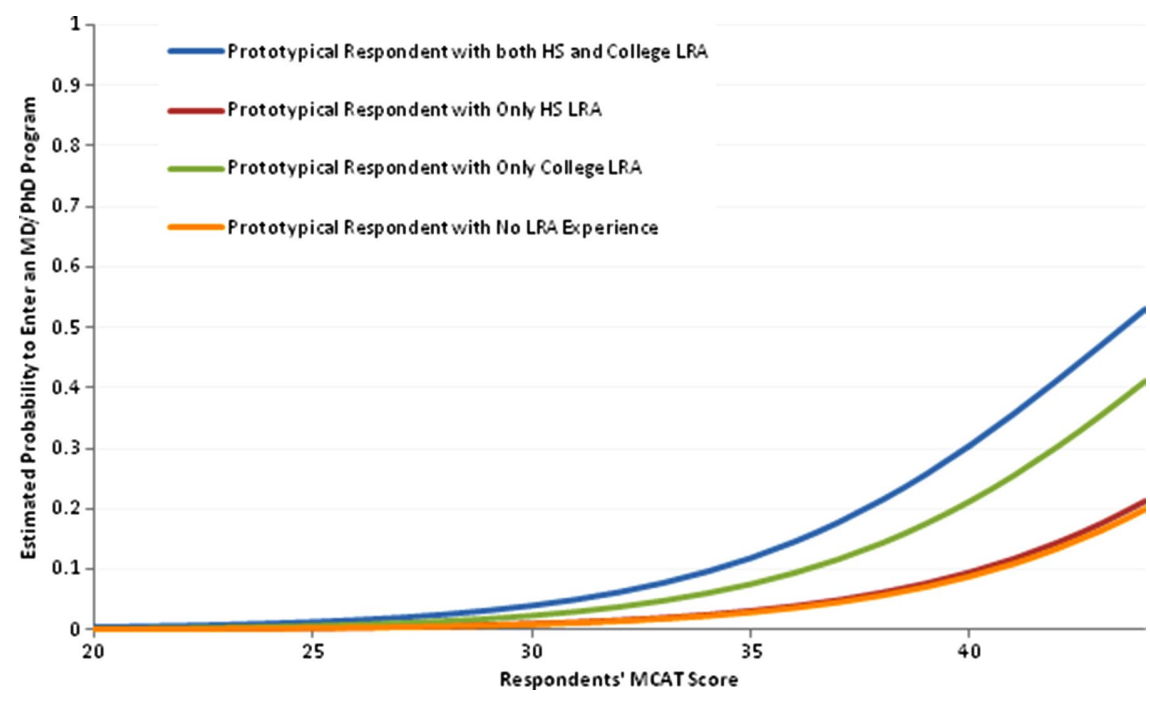

FIGURE 1. Fitted probability that a prototypical PMQ respondent enters an MD/PhD program with parameter estimates taken from model 5 . Other variables in the model were set to sample means.

Examining the year-by-year minimum and maximum odds ratios for the variables both HSSLRA and CLRA, only CLRA, and only HSSLRA, we can define three ranges of odds ratio values [3.91, 5.18], [2.21, 3.49], and [0.65, 1.55], respectively. Some variation in the odds ratios is expected from year to year, but on balance, the odds ratio ranges for the three variables show no overlap and lend further support to the robustness of the odds ratio values calculated from the aggregated model 5 analysis and replicable nature of our findings over time.

Therefore, the results from model 5 fitted to the aggregate data set indicate that respondents with both HSSLRA and CLRA experiences have 4.50 times greater odds of matriculating into an $\mathrm{MD} / \mathrm{PhD}$ program than respondents not reporting an LRA experience. Respondents with Only CLRA experiences have 2.79 times greater odds. Respondents with only HSSLRA did not have significantly greater odds than no LRA respondents. Figure 1 is a graphical comparison of the estimated probabilities for four prototypical individuals from each of the four LRA experience groups with covariates set to identical values. The area between the estimated probability curve for both HSSLRA and CLRA (blue line) and only CLRA (green line) offers some indication of the "added value" of the HSSLRA experience for respondents who continue to pursue LRA experiences in college. Figure 1 also shows that levels of academic achievement/preparedness, as measured by MCAT scores, vary substantially among MD-PhD program enrollees and, importantly, the benefit of LRAs is evident across a wide range of MCAT scores. This finding suggests that students with coupled HSSLRA and CLRA experiences are predicted to have significantly greater likelihoods of enrolling in $\mathrm{MD} / \mathrm{PhD}$ programs, even over students who reported having a CLRA experience only.

Next, we used model 5 to examine our findings for the 2001-2006 data set stratified by the four racial/ethnic demographic groups. This stratified analysis allowed us to determine whether our findings for the predictive value of each of the three LRA categories (compared with neither HSSLRA nor
CLRA participation) observed in the analysis of model 5 shown in Table 4 were consistent across each of the four racial/ ethnic groups (Table 3). Each set of odds ratios showed that students with both HSSLRA and CLRA experience had the greatest odds of matriculating into an $\mathrm{MD} / \mathrm{PhD}$ program. Respondents reporting only CLRA experiences had highly significant though lower odds of matriculating into an $\mathrm{MD} / \mathrm{PhD}$ program. Respondents with only HSSLRA experiences did not appear to be different from respondents with no LRA experiences in terms of their probability of matriculating into $\mathrm{MD} / \mathrm{PhD}$ programs.

Finally, regarding the second research question, the results indicate that among Black/African-American (non-Hispanic) respondents, those in the both HSSLRA and CLRA group had 3.6 greater odds of matriculating into an $\mathrm{MD} / \mathrm{PhD}$ program than no LRA respondents, while those in the only CLRA group had 2.82 greater odds. Among Hispanic/ Latino/a respondents, the results are even more pronounced. Respondents in the both HSSLRA and CLRA group had 5.37 times greater odds of matriculating into an $\mathrm{MD} / \mathrm{PhD}$ program than no LRA respondents, while respondents reporting only CLRA experiences had 2.55 times greater odds of $\mathrm{MD} / \mathrm{PhD}$ matriculation.

\section{CONCLUSIONS}

Through this study, we found that respondents reporting both HSSLRA and CLRA participation were more than four times more likely to matriculate into an $\mathrm{MD} / \mathrm{PhD}$ programs than their peers who did not report LRA experiences. Respondents who reported only CLRA participation were nearly three times more likely than no LRA participants to enter MD/PhD programs. Respondents reporting only HSSLRA participation did not have an $\mathrm{MD} / \mathrm{PhD}$ matriculation rate any different than no LRA participants. In light of these findings, it appears that the HSSLRA experience serves a vital purpose, one of helping young people to decide on whether research suits their future career paths. Their HSSLRA participation may reinforce their desire to enter the life sciences research career path and/or provides them with more information to make informed choices about their college education in this arena. The importance of such experiences in validating prior interests and providing information critical for the development and pursuit of career goals should not be minimized. Prior research has corroborated the importance of such programs for increasing secondary students' interest in science careers by providing them with close mentorship and hands-on experience with authentic scientific endeavors (Stake and Mares, 2001; Winkleby et al., 2009; Sadler et al., 2010). Another possible explanation for these findings is that participation in a research-intensive apprenticeship or internship could help students develop-or could even reinforce-a cognitive scheme for a research career. This is explained in part by prior research that has found that secondary students' confidence for doing science increases 
after participation in OST research programs (Templin et al., 1999; Rohrbaugh and Corces, 2011) and science-focused activities (Bhattacharyya et al., 2011). This is further elucidated, particularly as it relates to underrepresented minorities in STEM, through social cognitive career theory, an analytic framework that posits that an individual's self-efficacy beliefs as shaped by different learning experiences can directly influence the types of interests that individual will develop and, in turn, which career or academic path he or she will choose to follow (Lent et al., 1994; Lent 2005). In other words, this theory sheds light on how activities or supports, such as an HSSLRA, have the potential to bolster individual self-efficacy or help individuals visualize a particular role, such as that of a scientist or doctor, which can ultimately lead to the formation of vocational interests and pursuit of activities that are congruent with those interests.

Laboratory research apprenticeship experiences are examples of immersive educational programs that allow young people to access the research environment and the professionals within these environments. Programs of this type are especially important for youth who may not have regular contact with individuals who possess backgrounds in the sciences and engineering. Informal conversations and advice from experienced individuals may prove invaluable for someone with an interest in pursuing a similar career path. It is also commonly understood that LRA experiences can serve to enhance college applications and open doors beyond high school. This could be particularly beneficial for minority or underprivileged students who may not have access to the type of support and mentoring that could facilitate their pursuit of and persistence in STEM academic study at the postsecondary level.

The results from the disaggregated racial/ethnicity analysis presents a very similar picture across all four demographic groups, although the impact to African-American students appeared to be somewhat less than for Latino/a students (further research examining this differential impact of HSSLRAs for Latino/a(s) and African-American students appears to be warranted). Youth with HSSLRA experiences consistently matriculate into $\mathrm{MD} / \mathrm{PhD}$ programs at greater rates than their peers in all other groups across the entire sample. The reader should bear in mind that these results are consistent across PMQ cohorts spanning 6 years tracked longitudinally from 2001 to 2012 While these outcomes were found to be statistically significant, a greater type of significance is likely at play for young people.

Possessing firsthand experience of a career option most certainly opens more than just doors. It offers these young people the opportunity to gain firsthand knowledge from others who have been successful in this career path. While the statistics tell one story of an apprenticeship experience impacting the career decisions of young people, a critical component of these types of experiences is at the interpersonal level. High school youth have the opportunity to hear directly from those who have gone before what it takes to be successful. Wide-ranging advice that often includes academic preparation is commonly shared. Entry into an MD/PhD program is extremely competitive. Those lacking a strong academic footing in high school often do not have the time and resources to make up this ground in college. In other research on success in introductory college science course work, the importance of high school calculus course work has been established (Sadler and Tai, 2007). A lack of precollege academic preparation often sets off a "domino reaction," leaving young people without a strong high school preparation lacking the time and resources to enter a scientific career path. Helping young people gain experience is important; providing them the information necessary to formulate a solid plan of academic preparation is essential. By offering students precollege experiences with scientific research, the life sciences can give the young people the gift of time, enough time to establish the type of academic background necessary for success.

Further research is needed to elaborate on the relationship between science experiences at the precollege level and matriculation into STEM research careers and to flesh out the different types of high school research apprenticeships and their relative impacts.

\section{ACKNOWLEDGMENTS}

This study is based on data provided by the AAMC, and is supported by the NIH (NIGMS 1 R01 GM094535-01). R.H.T., X.K., C.E.M., K.P.D., and D.M.R. received additional support from the National Science Foundation (NSF), the S. D. Bechtel Jr. Foundation, and the Robert N. Noyce Foundation. The views expressed herein are those of the authors and do not necessarily reflect the position or policy of AAMC, NIH, NSF, the S. D. Bechtel Jr. Foundation, or the Noyce Foundation.

\section{REFERENCES}

Abraham LM (2002). What do high school science students gain from fieldbased research apprenticeship programs? The Clearing House: A Journal of Educational Strategies, Issues and Ideas, 75, 229-232.

Andriole DA, Whelan AJ, Jeffe DB (2008). Characteristics and career intentions of the emerging MD/PhD workforce. J Am Med Assoc 300, 11651173

Aschbacher PR, Li E, Roth EJ (2010). Is science me? High school students' identities, participation and aspirations in science, engineering, and medicine. J Res Sci Teach 47, 564-582.

Bakken LL, Byars-Winston A, Gundermann DM, Ward EC, Slattery A, King A, Scott D, Taylor RE (2010). Effects of an educational intervention on female biomedical scientists' research self-efficacy. Adv Health Sci Educ 2(15), 167-183.

Bauer KW, Bennett JS (2003). Alumni perceptions used to assess undergraduate research experience. J Higher Educ 74, 210-230.

Bhattacharyya S, Mead T, Nathaniel R (2011). The influence of science summer camp on African-American high school students' career choice. J Sch Sci Math 111, 345-353.

Chubin DE, DePass AL, Blockus L (2009). Understanding Interventions That Broaden Participation in Research Careers, Vol. 3, Summary of a Conference, Bethesda, MD: American Association for the Advancement of Science.

Dabney KP, Tai RH, Almarode JT, Miller-Friedmann JL, Sonnert G, Sadler PM, Hazari Z (2012). Out-of-school time science activities and their association with career interest in STEM. Int J Sci Educ 2, 63-79.

Dabney KP, Tai RH, Scott MR (2016). Informal science: family education, experiences, and initial interest in science. Int J Sci Educ, Part B: Commun Public Engage 6, 263-282.

Davis DD (1999). The research apprenticeship program: promoting careers in biomedical sciences and the health professions for minority populations Paper presented at the Annual Meeting of the American Educational Research Association, held April 19-23, 1999, in Montreal, Ontario. 
R. H. Tai et al.

Duffus WA, Trawick C, Moonesinghe R, Tola J, Truman BI, Dean HD (2014). Training racial and ethnic mintority students for careers in public health sciences. Am J Preventative Med 47, S368-S375.

Hernandez PR, Schultz PW, Estrada M, Woodcock A, Chance RC (2012) Sustaining optimal motivation: a longitudinal analysis of personal and contextual predictors of achievement goals. J Educ Psychol 105, 1-36.

Herrera FA, Hurtado S (2011). Maintaining Initial Interests: Developing Science, Technology, Engineering, and Mathematics (STEM) Career Aspirations Among Underrepresented Racial Minority Students, Los Angeles: University of California, Los Angeles.

Hosmer DW, Lemeshow S (1980). A goodness of fit test for the multiple regression model. Commun Stat A10, 1043-1069.

Humes KR, Jones NA, Ramirez RR (2011). Overview of Race and Hispanic Origin: 2010-Census Briefs (C2010BR-02) Washington, DC: U.S. Department of Commerce, Economics and Statistic Administration, U.S. Census Bureau.

Hunter AB, Laursen SA, Seymour E (2006). Becoming a scientist: the role of undergraduate research in students' cognitive, personal and professional development. Sci Educ 91, 36-74.

Knezek G, Christensen R, Tyler-Wood T, Periathiruvadi S (2013). Impact of environmental power monitoring activities on middle school student perceptions of STEM. Sci Educ Int 24, 98-123.

Kong X, Dabney KP, Tai RH (2013). The association between science summer camps and career interest in science and engineering. Int J Sci Educ 4, 54-65.

Lent RW (2005). A social cognitive view of career development and counseling. In Career Development and Counseling: Putting Theory and Research to Work, ed. SD Brown and RW Lent, New York: Wiley, 101-127.

Lent RW, Brown SD, Hackett G (1994). Toward a unifying social cognitive theory of career and academic interest, choice, and performance. $\mathrm{J}$ Vocat Behav 45, 79-122.

Lopatto D (2004). Survey of undergraduate research experiences (SURE): first findings. Cell Biol Educ 3, 270-277.

Maltese AV, Tai RH (2011). Pipeline persistence: examining the association of educational experiences with earned degrees in STEM among U.S. students. Sci Educ 95, 877-907.

Menard S (2001). Applied Logistic Regression Analysis, 2nd ed., Thousand Oaks, CA: Sage.

National Science Board (2007). A National Action Plan for Addressing the Critical Needs of the U.S. Science, Technology, Engineering, and Mathematics, Education System, Arlington, VA: National Science Foundation.
National Science Foundation (2013). Women, Minorities, and Persons with Disabilities in Science and Engineering. Washington, DC: National Center for Science and Engineering Statistics.

Pedhazur EJ (1997). Multiple Regression in Behavioral Research: Explanation and Prediction, 3rd ed., South Melbourne, Australia: Thomson Learning.

Rodrigues J, Sengupta A, Mitchell A, Kane C, Kane C, Maxwell S, Cameron H, Ross M, Ford M (2009). The Southeast Scotland Foundation Doctor Teaching Programme-Is "near-peer" teaching feasible, efficacious and sustainable on a regional scale? Med Teach 31(2), 51-57.

Rohrbaugh MC, Corces VG (2011). Opening pathways for underrepresented high school students to biomedical research careers: the Emory University RISE program. Genetics 189, 1135-1143.

Russell SH, Hancock MP, McCullough J (2007). Benefits of undergraduate research experiences. Science 316, 548-549.

Sackes M, Trundle KC, Flevares LM (2009). Using children's literature to teach standard-based science concepts in early years. Early Child Educ J 36 , 415-422.

Sadler PM, Tai RH (2007). The two high-school pillars supporting college science. Science 317, 457-458.

Sadler TD, Burgin S, McKinney L, Ponjuan L (2010). Learning science through research apprenticeships: a critical review of the literature. J Res Sci Teach 47, 235-256.

Sevinc B, Ozmen H, Yigit N (2011). Investigation of primary students' motivation levels towards scence learning. Sci Educ Int 22, 218-232.

Stake JE, Mares KR (2001). Science enrichment programs for gifted high school girls and boys: predictors of program impact on science confidence and motivation. J Res Sci Teach 38, 1065-1088.

Tabak LA, Collins FS (2011). Weaving a richer tapestry in biomedical science. Science 333, 925-926.

Tai RH, Liu CQ, Maltese AV, Fan X (2006). Planning early for careers in science. Science 312, 1143-1144.

Templin MA, Engemann JF, Doran RL (1999). A locally based science mentorship program for high achieving students: unearthing issues that influence affective outcomes. Sch Sci Math 99, 205-212.

Winkleby MA (2007). The Stanford Medical Youth Science Program: 18 years of a biomedical program for low-income high school students. Acad Med 82, 139-145.

Winkleby MA, Ned J, Ahn D, Koehler AR, Kennedy J (2009). Increasing diversity in science and health professions: a 21-year longitudinal study documenting college and career success. J Sci Educ Technol 18, 535545 . 